\title{
CALCINOSIS
}

\section{(A review with reports of four cases)}

By Peter Kilburn, M.B., M.Ch.Orth., F.R.C.S.Ed.

Orthopaedic Registrar, Professorial Unit, Royal Southern Hospital, Liverpool

Calcinosis is a particular example of pathological calcification, in which multiple calcareous deposits occur in the skin, subcutaneous tissues and in the more deep-seated interstitial connective tissues. The condition was described by Weber in 1878 , when he reported a case of calcinosis universalis occurring in association with sclerodactylia (Weber, I 878).

\section{Pathology}

This deposition of calcium in soft tissue is a chronic condition tending to be slowly progressive. The mechanism by which calcium salts are laid down in these abnormal sites is unknown and, despite extensive biochemical investigations, no significant departure from the normal can be detected in the large majority of patients. X-ray diffraction studies and chemical analysis indicate that deposits of calcium salts in both normal and abnormal sites have the same physical and chemical structure (Cornbleet et al., 1949; Atkinson and Weber, 1938).

It has been customary in the past to divide cases of calcinosis into two fairly well-defined groups, viz. calcinosis universalis and calcinosis circumscripta (Versé, I912; Steinitz, 193I). In such a classification the following points of contrast appear:

\section{Calcinosis Circumscripta}

This occurs most often in adult females, the ratio of females to males being approximately $6: 1$. In this form the deposits are limited to the skin and subcutaneous tissues of the upper extremity, especially the fingers. The condition bears a superficial resemblance to gout (' calcium gout').

\section{Calcinosis Universalis}

This condition is uncommon and is associated with widespread deposits of calcium salts in the skin, subcutaneous tissues and fascia. The limbs bear the brunt, the head and trunk being usually spared. The generalized form occurs more frequently in children, especially males. Calcinosis has been recorded in children under the age of two by several observers (Tisdall and Erb, 1924; Swanson et al., I933).

It is now felt that this division into universal and circumscript forms is undesirable, as it does not take into account the many transitional forms of the disease process, as well as carrying no diagnostic connotation: similar types of soft-tissue calcification may occur, e.g. in hypervitaminosis D, dermatomyositis, renal insufficiency, hyperparathyroidism and widespread carcinomatosis. The close association between soft-tissue calcification and conditions such as scleroderma (Thibierge and Weissenbach, I9II) and Raynaud's disease (Logan, 1924; Langmead, 1930; Durham, r928) has been observed for many years, but doubt has recently been cast on the association between calcinosis and Raynaud's disease by Cole (Cole, I953), who considers, after a close study of the reported cases, that this, in fact, represents a developing scleroderma. Attention has been recently focused again on the question of soft-tissue calcification and its relation to the collagen diseases in a thoughtprovoking paper by Clayton E. Wheeler and his colleagues (Wheeler et al., I952). These workers are not prepared to recognize idiopathic calcinosis as a clinical entity and they argue that soft-tissue calcification is always secondary to some other condition and that the primary cause can nearly always be elucidated if an adequate search is made. They classify the conditions predisposing to calcinosis into two main groups:

(I) Tissue injury, either (a) local, due to known causes, i.e. dystrophic calcification, or (b) widespread tissue injury, due to unknown causes, and in this latter group are included the collagen diseases.

(2) Conditions associated with abnormal calcium and/or phosphorus metabolism.

In I9I9 Mme. Déjerine and her co-workers wrote a comprehensive account of soft-tissue calcification in patients with cord lesions (Déjerine et al., 1919) and Liberson (1953) described softtissue calcification in 30 paraplegics. The mech- 
anism whereby this calcium is laid down is completely unknown, the deposition of calcium salts is not found above the level of the lesion nor do biochemical studies show any abnormality.

It is of interest to note that Van Wagtendonk and his colleagues (Van Wagtendonk et al., 1944 and 1947) reported a possible deficiency disease in guinea pigs associated with extensive deposition of calcium salts when these animals were kept on a restricted diet. If cream was subsequently administered to these animals, the deposits disappeared. Burnett (quoted by Cecil, 1955) has reported a syndrome of hypercalcaemia without hypercalcuria, but with renal insufficiency and calcinosis, in patients with peptic ulceration whose régime consists of an excessive milk intake associated with absorbable alkalis. It is clear, therefore, that the deposition of calcium salts in abnormal sites represents the end stage of many pathological states.

\section{Clinical Features}

The earliest symptom referable to the calcium deposits is frequently a localized area of skin tenderness and examination at this stage reveals multiple discrete stony-hard subcutaneous nodules; these are of varying sizes and pleomorphic, but with a tendency to be flat and to form plaques. The smaller nodules are mobile, but the larger ones are usually tethered to the deep structures. Ulceration of the skin over the more superficial nodules is a common occurrence, with the formation of painful shallow ulcers which exude calcareous material, after which they heal with dense scarring. Limitation of joint movement may be marked, due to the thick plaques of calcium in the vicinity of the joint, together with post-ulceration scarring and muscle atrophy. The distribution of the lesions is characteristic: the deposits are most frequent around the elbows, knees, buttocks and shoulders, whilst the trunk, face, scalp and viscera are nearly always spared.

\section{Biochemical Studies}

Estimations of serum calcium, phosphorus and alkaline phosphatase are normal in those cases of calcinosis associated with the collagen disorders; there is thus no evidence that disturbed levels of these minerals are significant aetiological factors in the laying down of calcium in these extraordinary sites. In these cases metabolic studies are either normal or else show a tendency to retain calcium (Atkinson, 1938; Bauer, 1931 ; Brooks, 1934). Of course, altered serum levels of calcium and phosphorus and alkaline phosphatase are to be found in those cases secondary to renal or parathyroid disease.

\section{Treatment}

Unfortunately, there is no specific treatment for this distressing condition. Local removal of the calcium deposits is always ineffective and is a waste of time. ACTH is worth a trial in those cases which are secondary to one of the collagen diseases and Briggs and Illingworth (Briggs and Illingworth, 1952) reported a case of calcinosis associated with dermatomyositis which showed regression of the calcium deposits after ACTH therapy. Low calcium diets are ineffective, as are ketogenic diets and the administration of ammonium chloride and sodium acid phosphate.

\section{Case. No. I (Figs. I to 3)}

Male patient, J. C. Aet. 18 years. Towards the end of 1947 began to complain of pain in the legs and jaw, followed by swelling and stiffness of joints-knees, ankles, elbows and wrists.

Admitted to hospital 31.3.48. Was then pale, wasted and febrile with swelling and stiffness of above-mentioned joints and stiffness of temperomandibular joint and neck. Spleen, liver and lymph glands not palpable. No evidence of carditis. X-ray showed decalcification of bone. Mantoux and W.R. negative. Diagnosed as rheumatic polyarthritis.

X-ray in December 1949 showed extensive generalized decalcification with patch of calcifica tion just above left ankle. (Calcified shadows iळ.left renal area and over the sacrum.)

Followed up at the out-patient clinic, when stiffness of hips and spine was noticed. In May r95 I numerous subcutaneous nodules confined to the right forearm detected (Fig. I). Patient said they had gradually appeared over the previous year.

$\mathrm{X}$-ray of limbs showed generalized osteoporosis and that the nodules in the right forearm were calcified. Sheets of calcification were also present in both thighs and left upper arm.

Biopsy of Subcutaneous Nodule, Right Arm. Gross appearance: An irregular flat mass of fibrofatty tissue $2 \mathrm{~cm}$. square. On section there are throughout several irregular calcified masses of white tissue surrounded by hyaline connective tissue.

Microscopic Examination. The white areas are irregular nodules of amorphous material containing calcium deposits lying in the plane of subcutaneous fat and surrounded by a marginal zone of connective tissue. No inflammatory reaction, no evidence of typical structure of the nodule of rheumatoid arthritis.

Investigations. Urine: normal. Urea clearance: I60 per cent. of average normal., Sulkowitch test: Grade 3 precipitation. Hb: 93 per cent. W.B.C.: normal. B.S.R.: $3^{8} \mathrm{~mm}$. in first hour (8.7.5 1 ; 


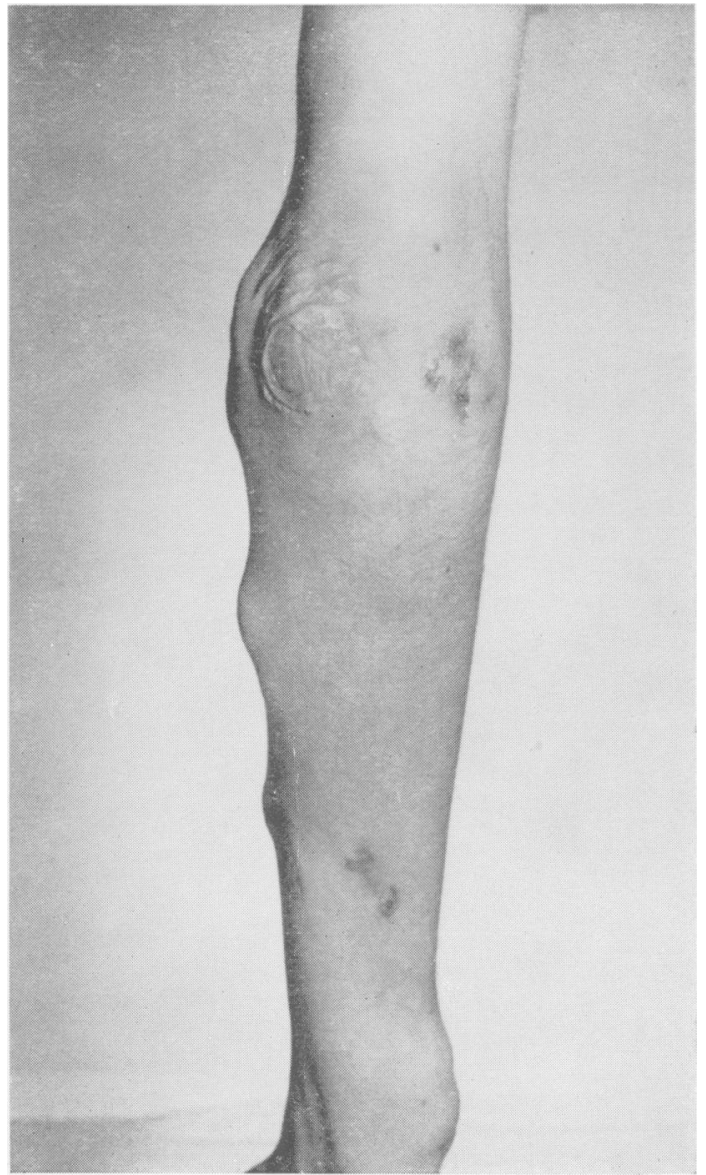

FIG. 1.-Photograph shows the swelling produced by masses of calcium and scarring.

I $\mathrm{mm}$. in first hour (23.7.5 I). Blood chemistry: blood urea, $32 \mathrm{mg}$. per cent.; alkaline phosphatase, I 4 units K.A.; serum protein, $7.3 \mathrm{~g}$. per cent.; serum calcium, II.2 mg. per cent.; serum calcium ions, $4.9 \mathrm{mg}$. per cent.; serum inorganic phosphate, $3.9 \mathrm{mg}$. per cent.

Stereoscopic films and tomograms of left thigh: Sheets of calcification in thigh are shown to be superficial. Calcification is most clearly shown at $3 \mathrm{~cm}$. from table top. Deeper than this only calcification superficially in curve of thigh can be seen.

In April I954 ACTH was started, but was later abandoned due to lack of response.

Fig. 2.-X-rays both thighs, 4.8.56.

Fig. 3.-X-ray arm, 4.8.56.

Comment. This is a case of extensive soft-tissue calcification developing two years after an attack of rheumatic polyarthritis and failing to show any response to either ACTH or sodium acid phosphate.

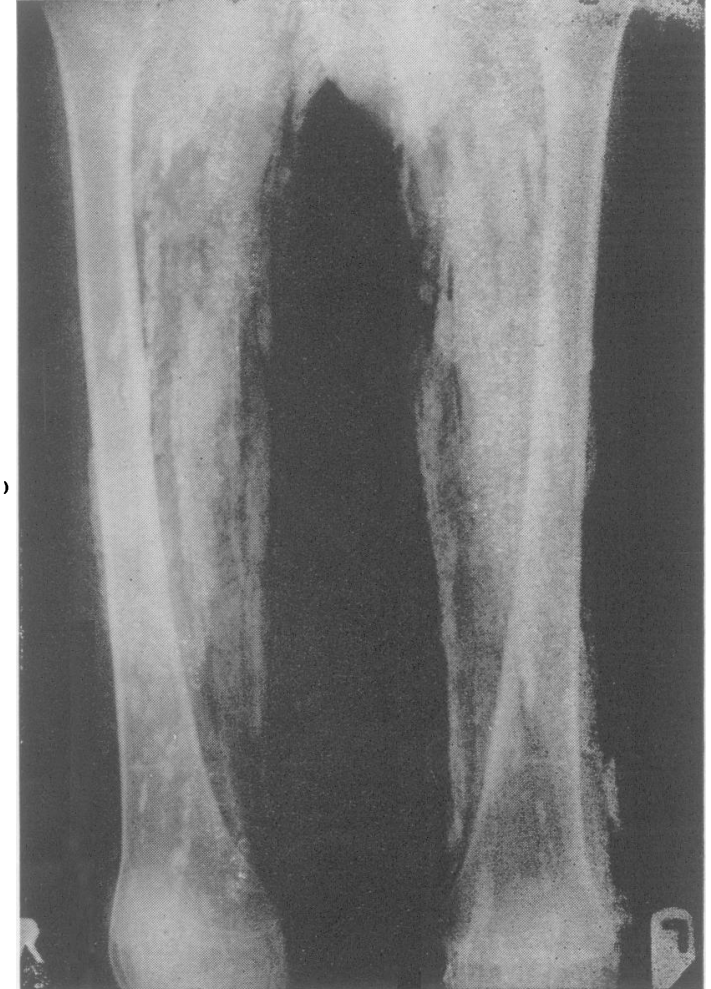

FIG. 2.-Extensive deposits of calcium in the soft tissues of both thighs.

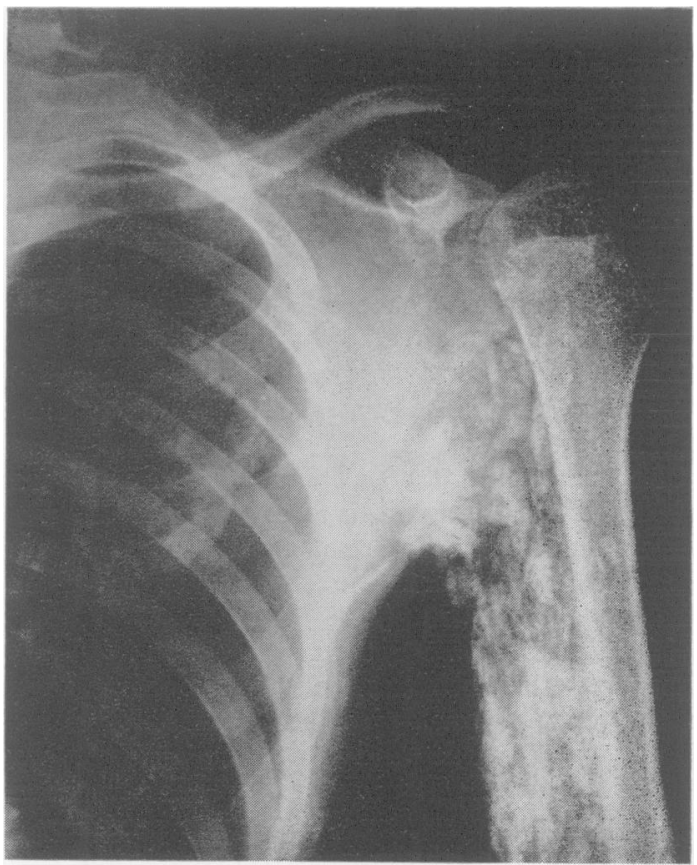

FIG. 3.-Deposition of calcium in soft tissues of upper limb. 


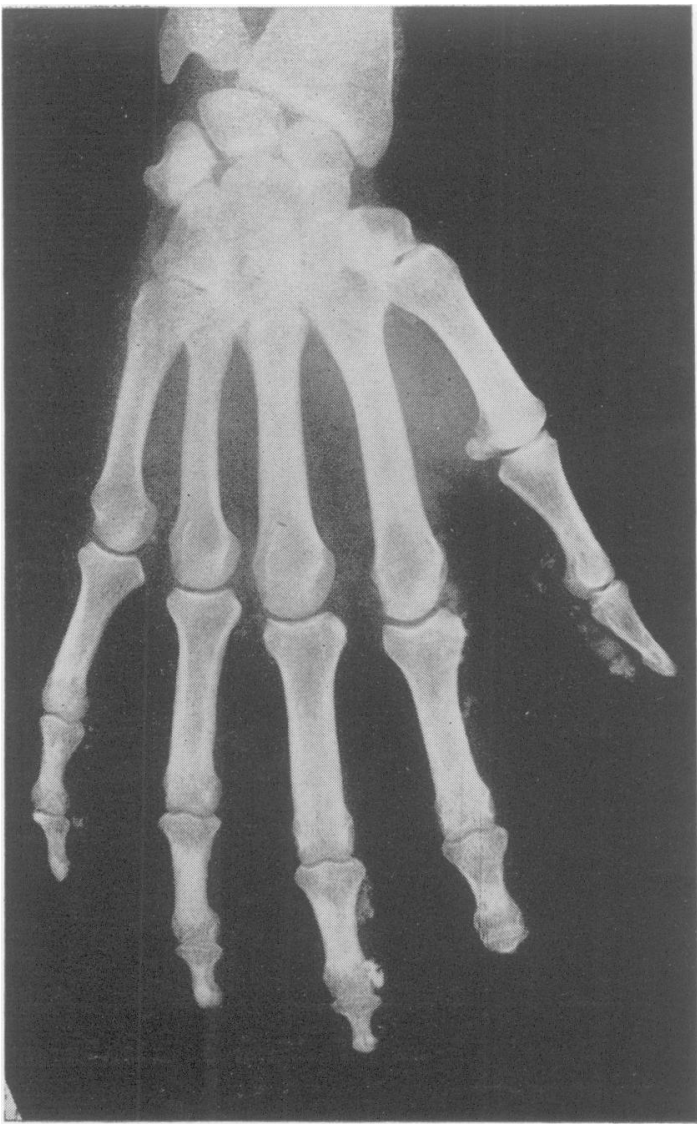

Fig. 4.-Showing soft-tissue calcification and atrophic changes in terminal phalanges.

\section{Case No. 2}

W. H., female. Aet. 53 years. This patient was admitted to hospital for gastro-intestinal investigation and, in addition to her complaints of vomiting and dysphagia, she gave a history of having had Raynaud's disease affecting both hands for 20 years and she had recently noticed that the digits had become rather pointed and shortened and had also become increasingly stiff.

On examination the skin over the fingers was white, shiny and smooth, closely bound down to the underlying tissues, the nails were fragile, and there were osteo-arthritic changes in the interphalangeal joints.

$\mathrm{X}$-rays which were taken on 13.7 .54 (Fig. 4) show soft-tissue calcification with atrophic changes in the terminal phalanges. A diagnosis of sclerodactyly was made and cortisone therapy was started. This resulted in a dramatic improvement in the patient's symptoms, but it was necessary to discontinue the therapy at the patient's own request, as she had become frightened after reading

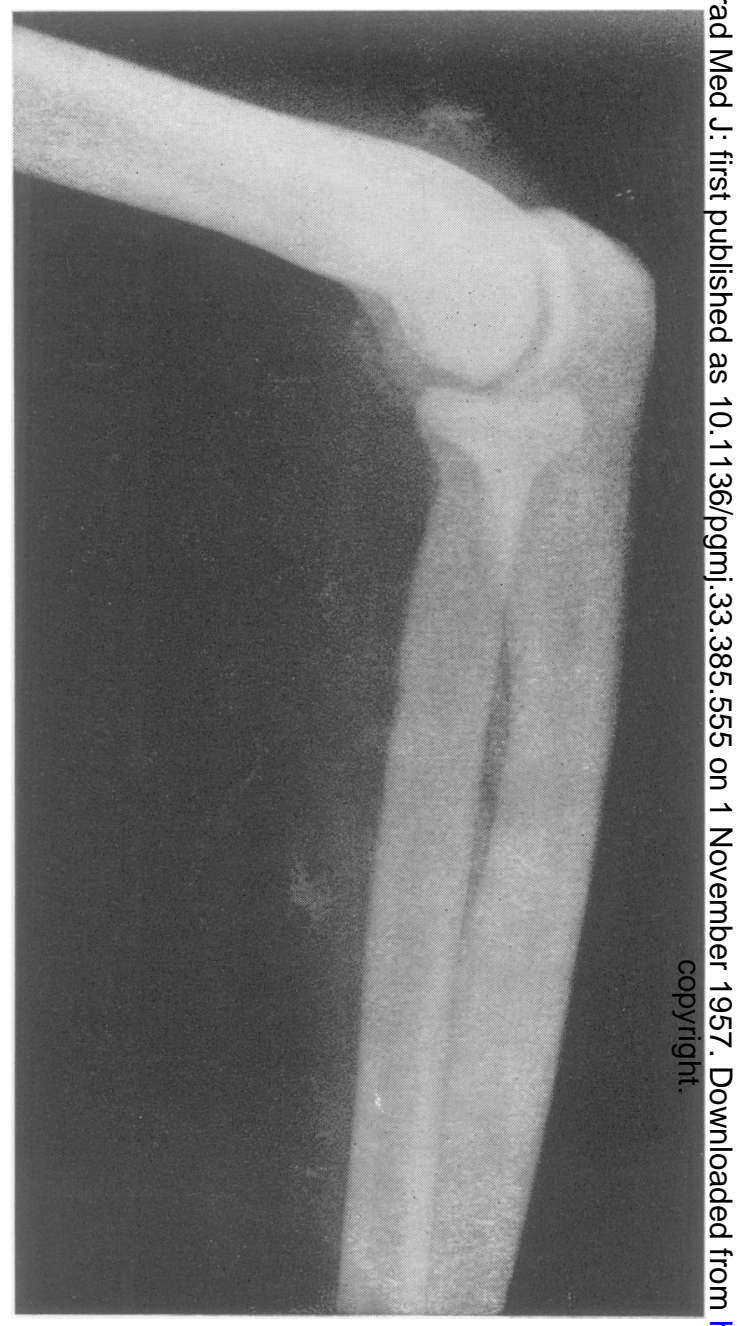

FIG. 5.-Showing vascular calcification and calcification of the olecranon bursa.

in the press about the dangers of cortisone therapy The patient died of coronary occlusion on 17.11 .56 .8

Comment. This case illustrates digital soft-tissue calcification developing in a long-standing case of 0 Raynaud's disease with secondary changes in the skin, suggesting a diagnosis of sclerodactyly.

Case No. 3

Male patient, E. H. H. Aet. 27 years. This ${ }^{N}$ patient was first seen in the orthopaedic out-N్心 patient department in December 1953, after he had injured his elbow.

$\mathrm{X}$-rays (Fig. 5) showed vascular calcification and calcification of the olecranon bursa. $\mathrm{He}$ was $\stackrel{\oplus}{\rightarrow}$ admitted to hospital and investigated.

Biochemistry on Admission. Blood urea, $60 \mathrm{mg}$. 


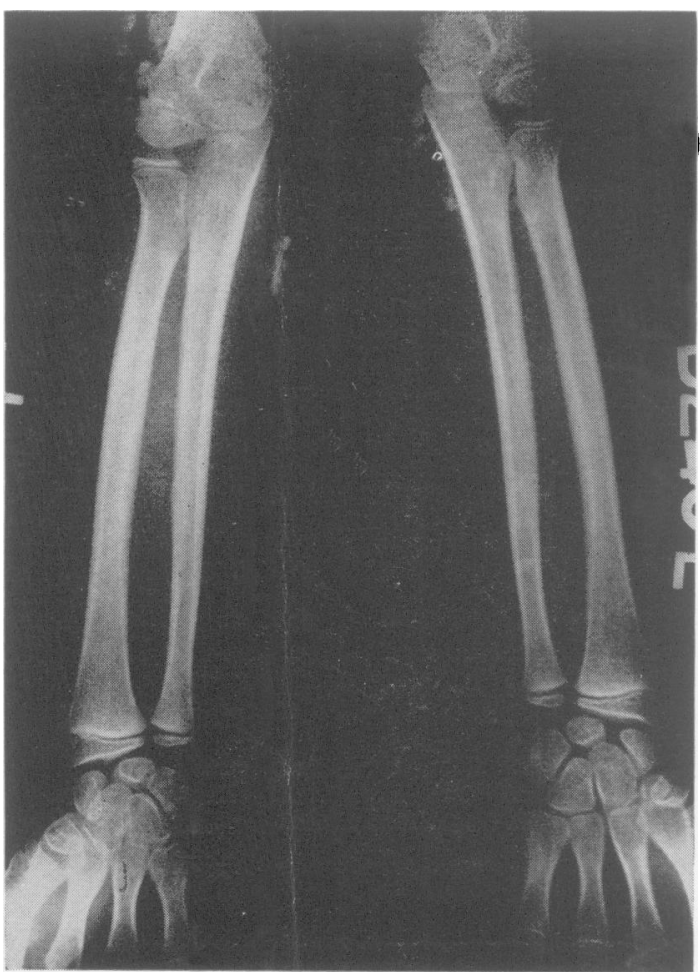

FIG. 6.-Showing calcium deposits in soft tissues of forearm and elbow.

per cent.; serum calcium, I0.5 mg. per cent.; serum alkaline phosphatase, 26 units ; serum phosphorus, 10 mg. per cent.; serum bicarbonate, I $5.7 \mathrm{ml}$. $\mathrm{CO}_{2}$ as bicarbonate; urinary calcium, $0.12 \mathrm{~g} . / \mathrm{diem}$.

This was taken to imply a state of renal insufficiency with acidosis, phosphorus retention and reactive parathyroid hyperplasia.

Biochemistry on 8.4.54. Serum bicarbonate, $60 \mathrm{ml} . \mathrm{CO}_{2}$; blood urea, $80 \mathrm{mg}$. per cent.; $\mathrm{Na}$, $320 ; \mathrm{K}, 27$.

I8.1.55, patient died.

Post-mortem findings were as follows: There was widespread soft-tissue calcification present which contained a white, softish material giving a reaction for calcium, phosphorus and carbonate.

Right kidney: Hypoplastic and was composed of a mass of tubules with no trace of glomerular structure.

Left kidney: Marked glomerular fibrosis with much interstitial fibrosis and round-celled infiltration.

Comment. This is an example of soft-tissue calcification occurring in association with chronic renal failure.
Case No. 4 (Fig. 6)

Female patient, B. H. Aet. nine years. At the age of three years it was first noticed that she had undue hardness of the muscles of both calves. This was noticed by her dancing instructor. At the age of four years she had a small soft swelling over the anterior aspect of the left leg, which gradually increased in size. In June 1953 it was incised and white chalky material was obtained. In October of that year she was seen at hospital because there was a continuous discharge from the calcified nodule. It was noticed that she was developing a similar lesion on the left buttock. An $\mathrm{X}$-ray of her skeleton at that time showed no further evidence of calcified lesions.

A diagnosis of calcinosis universalis was made. The biopsy, which was taken in March 1954, showed perivascular plasma and mononuclear cells with fibrosis and deposition of calcium in the fibrous tissues.

In July 1954 a calcium balance study was undertaken on high and low calcium intake and with and without cortisone treatment. At this time she was put on a maintenance dose of cortisone, $12.5 \mathrm{mg}$. twice daily.

At that time she had some difficulty in dorsiflexion of the left ankle, but this improved following treatment with cortisone.

By May 1955 she had deposits in both buttocks, both legs, right knee and right elbow. A deposit in the natal cleft was discharging.

In November 1955 the mass on the right buttock began to discharge and she was left with a large granulating mass. She was, therefore, readmitted in May 1956. She was operated on with removal of the calcified areas on the right buttock, left hip and right lower leg.

On 10.9.56 the lesion on the right popliteal fossa became painful, suggesting that secondary infection had taken place. She was once more given a course of penicillin and admitted on 11.9 .56 .

At a second operation on 17.9 .56 a mass behind the right knee was removed. Once more there was considerable bleeding. This time also the skin was closed with great difficulty. The knee had to be splinted in flexion for several days.

Cortisone was discontinued for a fortnight from the day of operation, but at the time of her discharge home she was taking cortisone once more and was walking around, although extension at the knee was still limited. The wound was well healed.

Diagnosis. Calcinosis universalis in association with dermatomyositis.

Comment. This girl has shown very great improvement in her general condition as a result of cortisone therapy, but there has been no evidence of resorption of the calcium deposits. 


\section{Summary}

I. The clinico-pathological features of calcinosis are discussed.

2. It is emphasized that in all cases a primary condition should be assiduously sought.

3. Four cases of soft-tissue calcification are described; in three of these cases there was evidence of a primary collagen disorder and in the fourth case the calcification was secondary to chronic renal failure.

\section{Acknowledgments}

I wish to express my sincere thanks to Prof. Bryan McFarland for his very great help and interest. I am also deeply indebted to Mr. G. Shatwell, Dr. G. S. Sanderson, Dr. S. Keidan, Mr. G. V. Osborne, Dr. R. W. Brookfield and Dr. E. L. Rubin and also Mr. A. G. O'Malley for allowing my access to their records and cases and for their kind permission to publish their cases.

Case No. 3 has been the subject of an article by Dr. R. W. Brookfield, Dr. E. L. Rubin and Dr. M. K. Alexander in the Fournal of the Faculty of Radiologists, 7, 2, 1955.

\section{BIBLIOGRAPHY}

ATKINSON, F. R. B., and WEBER, F. P. (1938), Brit. F. Derm., 50, 267.

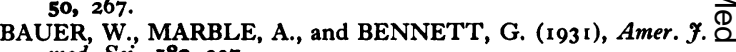
med. Sci., 182, 237.

BRIGGS, J. N., and ILLINGWORTH, R. S. (1952), Lancet, ii,

BROOKS, W. D. W. (1934), Quart. F. Med., 3, 293.

BURNETT, quoted by CECIL (1955), 'A Textbook of Medicine', Philadelphia. Saunders., p. $87 \mathrm{I}$.

COLE, W. R. (1953), Guy's Hosp. Rep., 102, 56.

CORNBLEET, T., REED, C. I., and REED, B. P. (1949), f. invest. Derm., 13, 171 .

DEJERINE, MME. CEILLIER A., and DEJERINE, Y. (I9I9), Rev. neurol. (Paris), 26, 399.

DURHAM, R. H. (1928), Arch. intern. Med., 42, 467.

LANGMEAD, F. S. (1930), Trans. med. Soc. Lond., 53. 67.

LIBERSON, M. (1953), F.A.M.A., 152, 1010.

LOGAN, J. R. (1924), Arch. Radiol., 28, 55.

STEINITZ, H. (1931), Ergebn. inn. Med. Kinderheilk, 39, 216.

SWANSON, W. W., FORSTER, W. F., and IOB, V. (1933) Amer. .7. Dis. Child., 14, 590.

THIBIERGE, G., and WEISSENBACH, R. J. (I9II), Ann. Derm. Syph. (Paris), 2, 129.

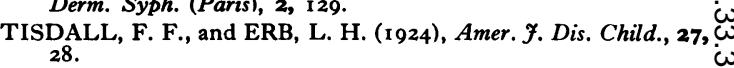

VAN WAGTENDONK, W. J., FREED, A. M., and BALLONE, C. E. (1944), Arch. Biochem., 5, 329. VAN WAGTENDONK, W. J., and FREED, A. M. (1947), G

VERSE, M. (1912), Beitr. path. Anat., 53, 212.

WEBER, H. (1878), KorrespBl. schweiz Arz. Basel, 8, 623.

WHEELF.R, C. E. (1952), Ann. Int. Med., 36, 1050.

\section{THYROID DISEASE}

(Postgraduate Medical Fournal, Fuly 1957)

Price: 3s. 9d., post free

DIAGNOSTIC PROCEDURES IN THYROID DISEASE

Russell Fraser, M.D., F.R.C.P., D.P.M.

THE PLACE OF RADIOACTIVE IODINE IN THE TREATMENT OF THYROID DISEASE

E. E. Pochin, M.D., F.R.C.P.

\section{ANTITHYROID DRUGS}

James Crooks, M.B., M.R.C.P. (Lond. and Ed.), F.R.F.P.S.G.

\section{SUBACUTE THYROIDITIS}

Selwyn Taylor, M.Ch., F.R.C.S.
RECENT WORK ON THYROID HORMONES

J. H. Wilkinson, B.Sc., Ph.D., F.R.I.C.

SOME UNUSUAL MANIFESTATIONS OF THYROID DISEASE

W. R. Trotter, D.M., M.R.C.P.

\section{CARCINOMA OF THE THYROID}

John E. Piercy, F.R.C.S., F.R.C.S.E.

LYMPHOID GOITRES

T. Levitt, M.A., F.R.C.S.Eng., F.R.C.S.Ed., F.R.C.S.I.

Published by

THE FELLOWSHIP OF POSTGRADUATE MEDICINE

60, Portland Place, London, W.1 